\title{
Cardiac arrest after trigger point injection
}

\author{
Tetik nokta enjeksiyonu sonrası kardiyak arrest
}

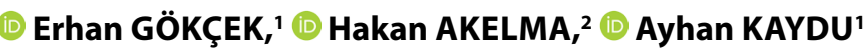

To the Editor,

Neurocardiogenic (vasovagal) syncop is a sudden loss of consciousness, occurring by decline of blood flow to the brain and the arterial blood pressure with neural mechanisms as a result of sudden vasodilation. ${ }^{[1,2]}$ Cardiac arrest can be observed by following bradycardia and hypotension in this case. When the syncope events observed in the operation room are examined, there are some reasons such as high doses of local anesthetics or opioid agents, intravenous injection of local anesthetics, painful injection, hypoxemia, hypercarbia, sympathetic blockade after intense sedation, autonomic impairment during recovery of neuroaxial blockade, cardiac arrest due to intense sympathetic blockade of psychogenic origin during spinal or epidural anesthesia. ${ }^{[1]}$ Vasovagal syncope has a mortality rate of $6 \%$, especially when the underlying cause is not known. ${ }^{[3]}$

When clinical image of vasovagal syncope is examined; short-term dizziness, nausea and weakness, and subsequent loss of consciousness and myoclonic movements are observed. In general, these syncopal episodes are temporary and do not recur frequently. The reason of half recurrent episodes is unknown. In this case report, it has been aimed to be discussed the vasovagal syncope that develops during the application of TNE procedure and proceeds to the cardiac arrest.

36-year-old female patient complained of widespread pain in especially left sides of bilateral neck and back region for the last 3 months. A physician and medical treatment was recommended for the patient who was not considered to have surgery operation after MR by orthopedic policlinic. The patient who could not receive treatment response was directed to our pain clinic for trigger point injection therapy. In the physical examination of the patient who had no history of resume and family history; American Society of Anesthesiologists (ASA) I, TA: 139/65 mmHg, Heart Rate: 72 / min. BMI: 27,8 kg / $\mathrm{m}^{2}$ (overweight) was natural to hear heart sounds. Preoperative laboratory findings were also detected within the normal limits and the patient was taken to the operating room. 20 Gauge angiocut was used to open the vein, and $100 \mathrm{cc} / \mathrm{h}$ of $0.9 \% \mathrm{NaCl}$ solution was added. Noninvasive blood pressure arterial (NIBP), pulse, peripheral oxygen saturation (SpO2) and electrocardiogram (ECG) monitoring were performed. The area to be treated was covered at a sterilized way by being cleaned with antiseptic solution containing povidone-iodine. Painful point was detected by examination and cardiac arrest occurred following bradycardia and continued during being applied TNE with 27 G, 1.5 inch (Germany) dental needle with $5 \mathrm{ml} 2 \%$ lidocain $+5 \mathrm{ml} 0.9 \% \mathrm{NaCl}$ by the anesthesiologist. The patient was immediately given $5 \mathrm{mg}$ ephedrine iv. With the mask, 100\% oxygen ventilation and cardiac massage started at 1: 5 . After $35 \mathrm{~s}$, the heart rate resumed and vital signs and consciousness became normal after an aggression period of $30 \mathrm{~s}$. Patients were discharged after followed up 24 hours in intensive care unit without any pathology found in vital or laboratory findings.

'Department of Anesthesia and Reanimation, Diyarbakır Selahaddini Eyyübi State Hospital, Diyarbakır, Turkey

${ }^{2}$ Department of Anesthesia and Reanimation, Diyarbakır Gazi Yaşargil Training and Training Hospital, Diyarbakır, Turkey

Submitted: 14.12.2018 Accepted after revision: 18.04.2019 Available online date: 26.06.2019

Correspondence: Dr. Erhan Gökçek. Diyarbakır Selahaddini Eyyübi Devlet Hastanesi, Anestezi ve Reanimasyon Kliniği, Diyarbakır, Turkey.

Phone: +90 - 412 - 2285430 e-mail: gokcekerhan_44@hotmail.com

(c) 2019 Turkish Society of Algology 


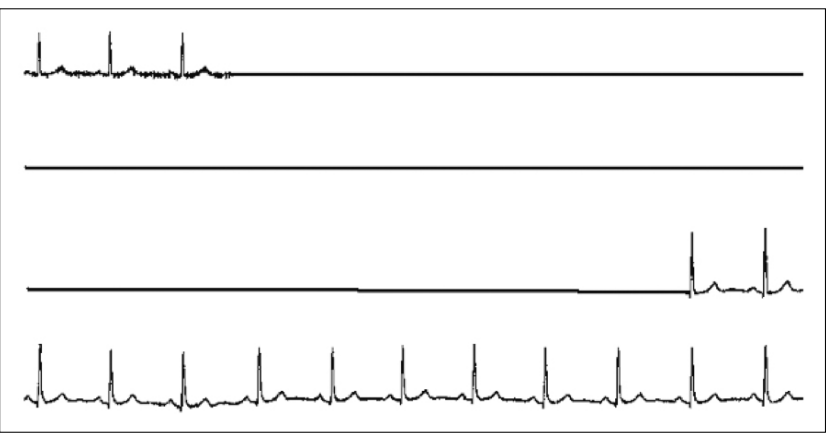

Figure 1. Asystole continuing 30 seconds.

Although vagal reflexes-related bradycardia is a common condition, associated syncope and cardiac arrest are rarely seen. Houk et al. have shown that sudden cardiac arrest may occur not only by ischemia, trauma, or local tissue damage, but also by neurogenic mechanisms. ${ }^{[4]}$ The most common cause of sudden cardiac arrest ( $80 \%)$ is coronary artery disease. When the literature isexamined, it has been shown that strabismus surgery, open abdominal operations, needle biopsies, foreign body aspiration, and even exercise and psychological reasons may occur in patients without previous cardiac complaints. ${ }^{[5]}$
As a result, regardless of the size of the operation to be performed, the patients should be effectively evaluated in all the surgical procedures and the necessary material for resuscitation during the procedure should be available.

\section{References}

1. Kinsella SM, Tuckey JP. Perioperative bradycardia and asystole: Relationship to vasovagal syncope and the BezoldJarisch reflex. Br J Anaesth 2001;86(6):859-68. [CrossRef]

2. Prakash ES, Madanmohan. When the heart is stopped for good: hypotension-bradycardia paradox revisited. Adv Physiol Educ 2005;29(1):15-20. [CrossRef]

3. Sprung J, Abdelmalak B, Schoenwald PK. Vasovagal cardiac arrest during the insertion of an epidural catheter and before the administration of epidural medication. Anesth Analg 1998;86(6):1263-5. [CrossRef]

4. Houk PG, Smith V, Wolf SG. Brain mechanisms in fatal cardiac arrhythmia. Integr Physiol Behav Sci 1999;34(1):3-9.

5. Baggot MG. General anesthesia, respiratory and cardiac standstill triggered by the extra-integumentary mechanical stimulation of foreign bodies in the airways. Med Hypotheses 1997;49(1):93-100. [CrossRef] 